D.O.I: $10.3895 /$ gi.v10i2.1657

\title{
PRÊMIO NACIONAL DA QUALIDADE: EXCELÊNCIA OU CONTROLE?
}

\section{NATIONAL AWARD OF QUALITY: EXCELLENCE OR CONTROL?}

\author{
Rudinei Machado de Abreu Junior ${ }^{1}$; Sidnei Manoel Rodrigues ${ }^{2}$; Bruno Henrique Figueiredo \\ Baldez $^{3}$; Luis Moretto Neto ${ }^{4}$ \\ ${ }^{1}$ Universidade Federal de Santa Catarina - CPGA/UFSC - Florianópolis - Brasil \\ rudineijr@gmail.com \\ ${ }^{2}$ Universidade Federal de Santa Catarina - CPGA/UFSC - Florianópolis - Brasil \\ sidneimr@sc.senai.br \\ ${ }^{3}$ Universidade Federal de Santa Catarina - CPGA/UFSC - Florianópolis - Brasil \\ bbaldez@gmail.com \\ ${ }^{4}$ Universidade Federal de Santa Catarina - CPGA/UFSC - Florianópolis - Brasil \\ moretto@cse.ufsc.br
}

\begin{abstract}
Resumo
O presente artigo analisa o modelo de gestão proposto pelos oito critérios de avaliação do Prêmio Nacional da Qualidade (PNQ) e o impacto nas formas de controle político-ideológico nas empresas participantes. Para tanto, inicialmente são examinados os conceitos de gestão da qualidade, que fundamentam o Prêmio Nacional da Qualidade, bem como os seus oito critérios e suas abordagens. Adicionalmente, a temática do controle é abordada sob a luz da Teoria Crítica do Controle, concebida como campo de estudo da Economia Política do Poder proposta por Faria (2004). Verificou-se que as práticas de gestão identificadas a partir da dissecação dos critérios do Prêmio Nacional da Qualidade contribuem não apenas para a intensificação, como também para sofisticação dos mecanismos de controle político-ideológico presentes nas organizações que se propõem a segui-las como referência de excelência em gestão. As conclusões do presente estudo suscitam questionamentos quanto à concepção hegemônica de excelência em gestão predominante nos estudos em administração, buscando contribuir para a construção de uma teoria organizacional que sirva à elucidação dos mecanismos de controle sobre o corpo e a mente dos trabalhadores e que instigue a emancipação destes frente a esta realidade.
\end{abstract}

Palavras-chave: controle organizacional; prêmio nacional da qualidade; economia política do poder.

\section{Introdução}

Os sistemas de controle, disciplina e sanção não distinguem as organizações por seu tipo, estrutura, tamanho ou finalidade. Organizações de toda classe estão sujeitas a estes sistemas e deles depende sua continuidade.

Isto posto, o controle social emerge como tema central na análise das organizações. Os novos modelos de gestão, surgidos a partir da extenuação do modelo taylorista-fordista, constantemente posicionam-se como alternativa flexível e humanizadora das relações de produção 
ao, supostamente, reduzirem o controle direto e coercitivo sobre o trabalhador.

Neste contexto, a gestão da qualidade surge como alternativa oposta aos preceitos tayloristas que, superada a fase de escassez de bens materiais e serviços essenciais, deixa de atender as demandas deste novo mercado consumidor.

Em seu discurso, a gestão da qualidade trás consigo o compromisso de promover a qualidade de produtos e serviços, democratizar a tomada de decisão, focar as necessidades do cliente, dar ênfase ao desenvolvimento dos trabalhadores e promover a substituição do controle coercitivo, ilustrado pela figura do supervisor, por um sistema de autocontrole.

No decorrer das décadas de 1970 e 1980, a gestão da qualidade alcança vasta popularidade nas organizações japonesas, norte americanas e européias, respectivamente. No Brasil, a abertura comercial, no início da década de 1990, representa o estopim para a internalização dos conceitos da gestão da qualidade pelas empresas nacionais, quando estas se vêem obrigadas a tornarem-se mais competitivas e a adaptarem-se a concorrência estrangeira.

$\mathrm{Na}$ esteira das premiações e certificações internacionais de qualidade e excelência em gestão, surge no Brasil, em 1992, o Prêmio Nacional da Qualidade (PNQ), idealizado pela Fundação Nacional da Qualidade (FNQ), fundada no ano anterior. O PNQ, que completa em 2013 sua $22^{\circ}$ edição, tem como propósito reconhecer as organizações referências em excelência da gestão no Brasil. Sua metodologia de avaliação consiste na análise das práticas gerenciais das empresas participantes a partir de oito critérios alicerçados nos preceitos da gestão da qualidade.

Ainda que seus conceitos e práticas tenham rapidamente se difundidos entre as empresas das principais economias de mercado do mundo, as críticas a gestão da qualidade vêm aumentando gradativamente, acompanhando o aprofundamento dos estudos elencados aos impactos da implantação dos sistemas de gestão da qualidade, especialmente aqueles voltados à analise dos sistemas de controle social nas organizações.

Destarte, este artigo tem por finalidade apresentar uma crítica ao modelo de gestão proposto pelo Prêmio Nacional da Qualidade, através de seus critérios definidores de excelência em gestão, objetivando avaliar o impacto nos sistemas de controle político-ideológico suscitada pela adoção das práticas de gestão identificadas nos critérios de avaliação do PNQ.

As análises serão conduzidas sob a luz, principalmente, mas não exclusivamente, da Economia Política do Poder, campo de estudos idealizado por Faria (2004), que busca construir uma Teoria Crítica do Controle. Nessa proposta teórico-metodológica, Faria (2004) aponta para 3 níveis interdependentes de controle: econômico, político-ideológico e psicossocial. Neste artigo, as análises restringem-se ao nível político ideológico e suas formas de controle.

Além dessa introdução, este artigo estrutura-se nas seguintes seções: (ii) gestão da qualidade: contexto histórico, princípios e críticas; (iii) Prêmio Nacional da Qualidade e seus 
critérios de avaliação; (iv) Controle organizacional na perspectiva da Economia Política do Poder; (v) Os critérios de excelência do PNQ e as formas de controle político-ideológicas; e

(vi) Considerações finais.

\section{Gestão da qualidade: contexto histórico, princípios e críticas}

As limitações do modelo de produção taylorista conduziram o surgimento dos modelos gerenciais que dariam forma à gestão da qualidade. Fundamentada em princípios inicialmente tidos como antagônicos ao taylorismo, a gestão da qualidade primaria pela autonomia e participação nos processos de trabalho, sobrepondo a vigilância dos supervisores pelo autocontrole por parte dos trabalhadores. Com tais características, a gestão da qualidade emergiu como uma sofisticação da gestão organizacional (CUNHA, J.; CUNHA M.; DAHAB, 2001).

A multiplicação de conceitos e teorias torna árdua a tarefa de precisar o significado do termo gestão da qualidade, extensamente tratado na literatura como Total Quality Management - TQM. Os conceitos formulados pelos chamados "gurus" da qualidade oscilam em sua amplitude e profundidade, porém, convergem em torno de três conceitos complementares, a saber: conformidade, adequação ao uso e satisfação do cliente (URDAN; WOOD JR., 1994).

A gestão da qualidade, no entanto, está longe de ser unanimidade para os teóricos da administração. Percepções críticas a respeito da gestão da qualidade alegam que esta não passa de uma versão sofisticada do taylorismo. Seus fundamentos, como o participacionismo, as equipes autogeridas e o autocontrole seriam, para os críticos, nada além de artimanhas psicológicas voltadas à aceitação voluntária dos interesses da gestão, à internalização do taylorismo e ao controle panóptico (CUNHA, J.; CUNHA M.; DAHAB, 2001).

No Quadro 1, a seguir, apresenta-se um comparativo entre os preceitos do taylorismo e os fundamentos da gestão da qualidade, primeiramente conforme concebida por seus defensores e, em seguida, na perspectiva dos autores que a entendem como uma intensificação do modelo taylorista.

\begin{tabular}{|c|c|c|}
\hline Tav & ade (versão oficial) & Oualidade (aoend \\
\hline Especialização & Multiespecialização & Substituibilidade dos $\mathrm{RH}$ \\
\hline Controle Hierárquico & Autocontrole & Controle panóptico \\
\hline Obediência & Envolvimento & Autotaylorização \\
\hline Ênfase na organização & $\begin{array}{c}\text { Ênfase no desenvolvimento dos } \\
\text { empregados }\end{array}$ & $\begin{array}{c}\text { Ênfase no controle individual para alcançar os } \\
\text { objetivos da empresa }\end{array}$ \\
\hline Autoridade & Democracia & Ilusão democrática \\
\hline Modernista & Pós-modernista & Neo-modernista \\
\hline
\end{tabular}

Fonte: Adaptado de Cunha, Cunha e Dahab (2001).

No Brasil, os primeiros passos em direção à qualidade começaram a ser dados no final da década de 1950, a partir da adoção da política de substituição das importações, com maior impacto junto às empresas estatais (FERNANDES, 2011). No entanto, foi somente em dezembro de 1990, 
com o lançamento da Política Industrial e de Comércio Exterior (PICE), promovendo a abertura do mercado às empresas estrangeiras, que as empresas brasileiras atentaram para a necessidade de reestruturação dos seus modelos de gestão e buscaram a adequar-se ao nível de competitividade internacional. Nesse momento, a qualidade de produtos e serviços e os custos de produção tornamse palavras de ordem nas empresas nacionais (URDAN; WOOD JR., 1994).

$\mathrm{O}$ esforço direcionado à internalização dos modelos gerenciais voltados à qualidade pelas principais empresas nacionais fomentou o desenvolvimento de programas e prêmios que visam o estímulo à adoção dos princípios de qualidade e produtividade, como Programa Brasileiro da Qualidade e Produtividade (PBQP) e o Prêmio Nacional da Qualidade, que serão apresentados na seção subsequente.

\section{Prêmio nacional da qualidade e seus critérios de avaliação}

O Prêmio Nacional da Qualidade, concedido pela Fundação Nacional da Qualidade, é realizado anualmente desde 1992 e constitui o maior reconhecimento público à excelência da gestão das organizações com sede no Brasil. A criação do PNQ decorre de um movimento internacional, a partir da década de 1980, pelo reconhecimento das empresas que primam pela excelência em gestão, como os prêmios Malcolm Baldrige National Quality Award, nos EUA, e o European Foundation for a Quality Management, na Europa (FNQ, 2012).

Conforme informações da Fundação Nacional da Qualidade (FNQ, 2012), o Prêmio Nacional da Qualidade possui quatro objetivos principais:

a) Estimular o desenvolvimento cultural, político, científico, tecnológico, econômico e social do Brasil;

b) Fornecer para as organizações um referencial (modelo), visando um aperfeiçoamento contínuo;

c) Conceder reconhecimento público e notório à excelência da qualidade da gestão para organizações de classe mundial;

d) Divulgar as práticas de gestão bem sucedidas, com vistas ao benchmarking.

As empresas candidatas ao PNQ submetem-se a uma profunda análise de sua gestão. A avaliação é realizada por meio de 10 etapas, que são apresentadas na Figura 1, a seguir: 
Figura 1 - Etapas de avaliação do Prêmio Nacional da Qualidade

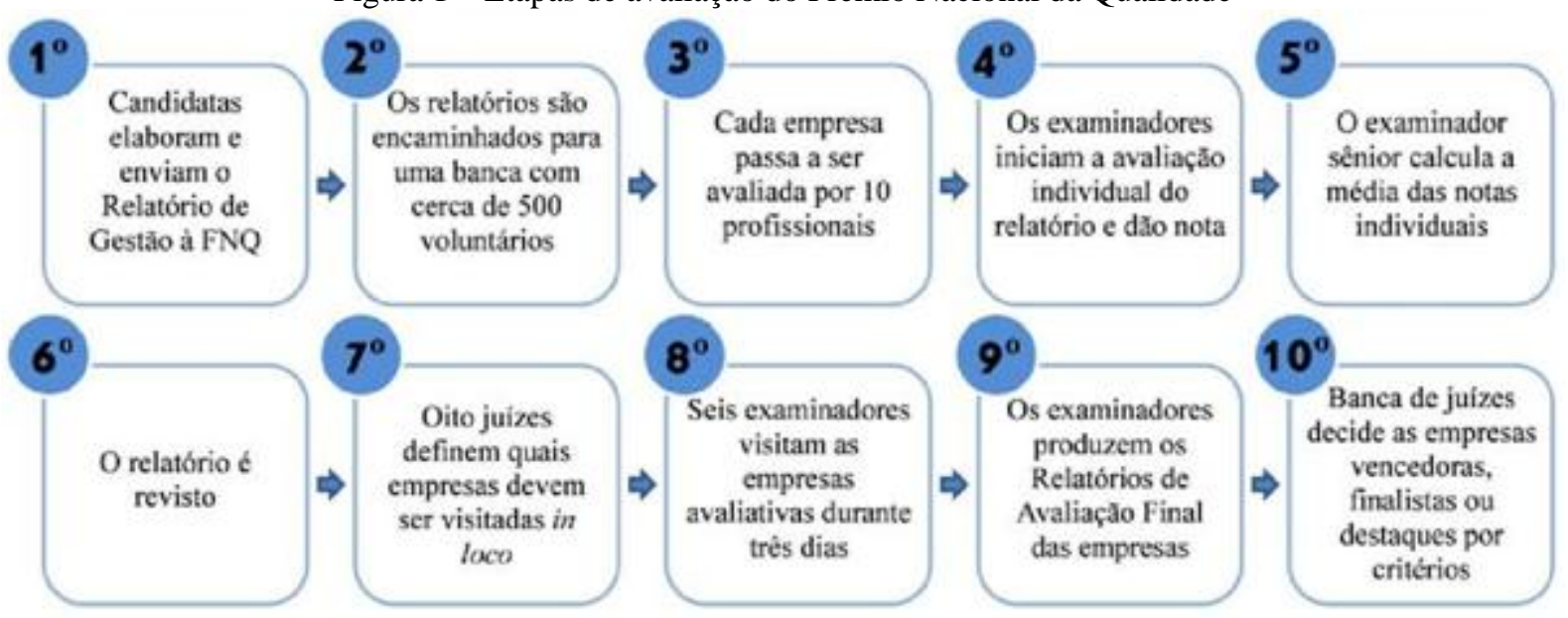

Fonte: Fundação Nacional da Qualidade (2012)

O Relatório de Gestão divide-se em duas partes. O ponto de partida é o levantamento do perfil da organização, que constitui uma apresentação geral das principais características e as fronteiras da organização avaliada. Em seguida, a organização deve descrever suas práticas de gestão e seus resultados, mapeados por meio dos oito critérios de excelência definidos pelo PNQ.

A partir da análise das descrições das práticas de gestão contidas em cada critério, os avaliadores do PNQ atribuem pontuações cujas máximas variam de acordo com cada critério, podendo alcançar uma pontuação total de até 1.000 pontos.

É fundamental ressaltar que os critérios do PNQ não possuem caráter prescritivo, ou seja, não há um modelo estruturado, sistemático, que descreva com exatidão as práticas de gestão que devem, invariavelmente, ser adotadas pelas organizações participantes.

O modelo de avaliação proposto através da elaboração do Relatório de Gestão consiste na resposta a uma série de questionamentos referentes a cada critério e, a partir das respostas das empresas participantes e da avaliação dos examinadores do PNQ, verifica-se a conformidade das práticas de gestão aplicadas pela empresa com os fundamentos da excelência em gestão.

A seguir, o Quadro 2 apresenta os critérios de avaliação do PNQ:

Quadro 2 - Critérios do Prêmio Nacional da Qualidade

\begin{tabular}{|l|l|l|}
\hline Critérios & Subcritérios de Análise & Pontuação \\
\hline Liderança & $\begin{array}{l}\text { (1.1) Governança Corporativa } \\
\text { (1.2) Exercício da liderança e promoção da cultura da excelência } \\
\text { (1.3) Análise do desempenho da organização }\end{array}$ & 110 pontos. \\
\hline Estratégias e Planos & $\begin{array}{l}\text { (2.1) Governança Corporativa } \\
\text { (2.2) Implementação das Estratégias }\end{array}$ & 60 pontos. \\
\hline Clientes & $\begin{array}{l}\text { (3.1) Imagem e Reconhecimento de Mercado } \\
\text { (3.2) Relacionamento com Cliente }\end{array}$ & 60 pontos. \\
\hline Sociedade & $\begin{array}{l}\text { (4.1) Responsabilidade Socioambiental } \\
\text { (4.2) Desenvolvimento Social }\end{array}$ & 60 pontos. \\
\hline Informações e & $\begin{array}{l}\text { (5.1) Informações da Organização } \\
\text { (5.2) Ativos Intangíveis e Conhecimento Organizacional }\end{array}$ & 60 pontos. \\
\hline
\end{tabular}




\begin{tabular}{|l|l|l|}
\hline Critérios & Subcritérios de Análise & Pontuação \\
\hline Conhecimento & & \\
\hline Pessoas & $\begin{array}{l}\text { (6.1) Sistemas de Trabalho } \\
\text { (6.2) Capacitação e Desenvolvimento } \\
\text { (6.3) Qualidade de Vida }\end{array}$ & 90 pontos. \\
\hline Processos & $\begin{array}{l}\text { (7.1) Processos Principais do Negócio e Processos de Apoio } \\
\text { (7.2) Processos Relativos aos Fornecedores } \\
\text { (7.3) Processos Econômico-financeiros }\end{array}$ & 110 pontos. \\
\hline Resultados & $\begin{array}{l}\text { (8.1) Resultados Econômico-financeiros } \\
\text { (8.2) Resultados Relativos a Clientes e ao Mercado }\end{array}$ & 450 pontos. \\
& $\begin{array}{l}\text { (8.3) Resultados Relativos à Sociedade } \\
\text { (8.4) Resultados Relativos às Pessoas } \\
\text { (8.5) Resultados Relativos a Processos } \\
\text { (8.6) Resultados Relativos a Fornecedores }\end{array}$ & \\
\hline
\end{tabular}

Fonte: Autoria própria (2013)

\section{Controle organizacional na perspectiva da economia política do poder}

A persistência dos preceitos tayloristas nas teorias organizacionais tradicionais tem propiciado a busca por novos caminhos no campo de conhecimento da administração. A tradição positivista hegemônica nos estudos em administração, constituída sobre o pilar da racionalidade utilitária, tem impossibilitado a emancipação de administradores e administrados (CANÇADO; TENÓRIO; PEREIRA, 2011).

Mesmo que os estudos fundamentados em críticas ao controle da força de trabalho tenham despontado ao longo de todo o século XX, foi apenas a partir da década de 1990 que os estudos críticos em administração elevam-se ao nível de subdisciplina do campo de estudos em administração (DAVEL; ALCADIPANI, 2003). No caso brasileiro, Paes de Paula (2008) ressalta que antes mesmo do surgimento da teoria crítica como subdisciplina da administração, autores como Alberto Guerreiro Ramos (1965), Maurício Tragtenberg (1974) e Fernando Claudio Prestes Motta (1987) já conduziam seus estudos voltados à emancipação e à construção de uma sociedade livre da dominação.

Vieira e Caldas (2006) propõem dois princípios básicos que conduzem a teoria crítica, a saber: (i) a orientação para a emancipação do homem na sociedade, e (ii) a manutenção do comportamento crítico. O dever dos estudos fundamentados na teoria crítica, portanto, estendem-se para além da investigação da racionalidade instrumental, das estratégias, instituições, comportamentos e políticas. Devem, sobretudo, desvendar os mecanismos de poder e as formas de controle, seja econômico, político, ideológico ou psicossocial, inerentes às relações de trabalho, com o propósito de compreender as organizações e seus desígnios (FARIA, 2009).

A perspectiva crítica questiona, enfaticamente, a racionalidade presente nas teorias administrativas tradicionais, visando expor as faces ocultas das estruturas de controle, dominação e desigualdades nas organizações (DAVEL; ALCADIPANI, 2003). 
Para Motta (1990 p. 19),

As ciências constituem parte do modo de dominação burocrático-meritocrático que caracteriza nossas vidas. Seu esforço continuado é o de tentar fundir a racionalidade substantiva na racionalidade instrumental, justificando determinado tipo de ordenação social voltada para a produtividade e o lucro.

Tragtenberg (2006) chama a atenção para o caráter dinâmico e transitório das teorias administrativas tradicionais que, para o autor, representam os interesses dos setores da sociedade detentores do poder econômico-político. Tragtenberg (2006, p. 109), ainda, acrescenta que as teorias administrativas tradicionais "constituem-se em repositório organizado de experiências cuja herança cumulativa é um condicionante das novas teorias, por exemplo, a persistência de aspectos tayloristas em Elton Mayo e na Escola Estruturalista".

Nesse sentido, o entendimento de controle organizacional na teoria crítica em administração conflita, diretamente, com a concepção de controle da perspectiva funcionalista, em que o controle é visto como necessário à manutenção e à sobrevivência da organização, efeito inelutável da sociedade organizacional (MARTINS, 2006).

Martins (2006) critica a visão funcionalista do controle por centrar-se nas necessidades organizacionais, ocultando o caráter opressor e alienante do controle. Silva e Silva (2011) observam que, mesmo quando discutem temas como qualidade de vida e satisfação no trabalho, a concepção funcionalista apenas "mascara" as formas de controle e dominação presentes nas organizações modernas.

Para Faria (2004 p.85),

[...] a ideologia da gestão capitalista, desde Taylor, tem por base o desenvolvimento de mecanismos de controle do processo e das relações de trabalho que devem ser utilizados pelos gestores. Ora físicos, ora psicológicos, ora de forma direta, ora de maneira mais sutil através de esquemas de participação, o fato é que, o controle e, em consequência, as relações de poder, fundamentam todo conjunto das propostas.

Leal (2003) atenta que as organizações se utilizam dos mecanismos de controle social para a manutenção da ordem, frente à intensa contraditoriedade quanto ao comportamento humano e coletivo que permeia as relações de produção nas organizações instituídas sob uma gestão capitalista.

Esses mecanismos de controle são comuns a todas as formas de organização, pois deles depende sua manutenção e sobrevivência. O que é determinante na análise do controle na teoria organizacional, no entanto, é minuciar até que ponto tais mecanismos estão perfeitamente claros para seus membros ou o quanto eles se encontram acaçapados no discurso democráticoparticipativo das práticas organizacionais modernas (FARIA, 2004). 
Para Faria (2004, p. 152),

\begin{abstract}
as metas de produção, a vigilância, as punições formais e as advertências, a disciplina, a hierarquia, a alienação, a propriedade e a posse dos meios de produção, a transmissão ideológica, as normas, os símbolos, os vínculos e os mecanismos de sedução são formas de expressão do controle contra possíveis atos de rebeldia. Como a rebeldia pode estar em qualquer lugar e pode ocorrer em qualquer época, o controle é uma atividade permanente da gestão capitalista.
\end{abstract}

Os mecanismos de controle aperfeiçoam-se conforme o desenvolvimento do capitalismo. Isso significa que os mecanismos presentes na Organização Científica do Trabalho, ou taylorismofordismo, não foram abandonados ou sequer substituídos, mas sim incrementados. A sofisticação desses mecanismos se dá de tal modo que torna a percepção de suas práticas inversamente proporcional à sua efetividade (FARIA, 2004).

Faria (2004) observa que o taylorismo-fordismo permanece como o sustentáculo da produção enxuta flexível, ou toyotismo. A maior participação, flexibilidade, mobilidade ou autonomia apregoada por esse modelo contemporâneo de produção não descaracterizam a Organização Científica do Trabalho. O que ocorre é a incorporação de novos mecanismos de controle aos já utilizados no taylorismo-fordismo. Dessa forma, ao invés de promover uma alternativa "humana" ao taylorismo-fordismo, o toyotismo constitui uma forma de super-taylorismo.

A respeito das formas de controle nas organizações contemporâneas, Invernizzi (2000, p.41) esclarece que

\footnotetext{
já não se trata de um controle direto e coercitivo sobre o trabalho individual, baseado na observação direta, nem na coerção por tempos padrões ou imposta pela cadeia, característicos do taylorismo-fordismo. Opera-se uma transição para o controle via organização do trabalho, sustentada na responsabilidade e autonomia do trabalhador frente a seu trabalho. O sistema de controle deixa de ser organizado centralmente para espalhar-se em redes pelo processo produtivo, formando um novo sistema auto-organizador descentrado.
}

Segundo Faria (2004, p.88), “para compreender o controle é necessário classificá-lo em seus níveis, suas formas e suas práticas". Nesse sentido, o autor propõe três níveis interdependentes para a análise do controle: (i) o nível econômico e suas relações de produção, propriedade e posse; (ii) o nível político-ideológico e a superestrutura construída a partir das relações de produção e sua institucionalização; e (iii) o nível psicossocial e a relação entre os sujeitos inseridos nos processos produtivos e políticos.

\title{
4.1. O controle político-ideológico nas organizações capitalistas
}

Neste artigo, abordaremos a dimensão político-ideológica e suas formas de controle, que sustentarão as críticas à consolidação do controle político-ideológico nas organizações, através da análise dos critérios de excelência do Prêmio Nacional da Qualidade.

A dimensão político-ideológica e suas quatro formas de controle definidas por Faria (2004): 
(i) hierárquico-burocrática; (ii) disciplinar; (iii) por transmissão ideológica; e (iv) por alienação, são detalhadas no Quadro 3, a seguir. Às análises dos critérios do PNQ, sustentadas nessas quatro diferentes formas de controles, foi reservada a Seção 5 deste artigo.

Quadro 3-Mecanismos de controle político-ideológico

\begin{tabular}{|c|c|}
\hline Forma de Controle & Mecanismos de Controle \\
\hline Hirárquico-burocrático & $\begin{array}{l}\text { Estrutura hierárquica, controle burocrático, regras, procedimentos, métodos de direção e } \\
\text { comando e os critérios de interpretação e julgamentos. }\end{array}$ \\
\hline Disciplinar & $\begin{array}{c}\text { Ações corretivas, mecanismos de punição aos transgressores, estímulos à cooperação, } \\
\text { ao alcance das metas determinadas e práticas de remuneração, incentivos e } \\
\text { reconhecimento. }\end{array}$ \\
\hline $\begin{array}{l}\text { Por Transmissão } \\
\text { Ideológica }\end{array}$ & $\begin{array}{l}\text { Criação e disseminação de valores, princípios e da cultura organizacional, estratégias de } \\
\text { treinamento, desenvolvimento e capacitação dos trabalhadores. }\end{array}$ \\
\hline Por Alienação & $\begin{array}{l}\text { Sequestro da subjetividade, através de suas cinco formas (FARIA; MENEGHETTI, } \\
\text { 2001): (i) pela identificação; (ii) pela essencialidade valorizada; (iii) pela colaboração } \\
\text { solidária; (iv) pela eficácia produtiva; e (v) pelo envolvimento total. }\end{array}$ \\
\hline
\end{tabular}

Fonte: Adaptado de Faria (2004)

\section{Os critérios de excelência do PNQ e as formas de controle político-ideológicas}

Nesta seção, discorreremos sobre cada uma das formas de controle da dimensão políticoideológica, as quais são: (i) hierárquico-burocrática; (ii) Disciplinar; (iii) por transmissão ideológica; e (iv) por alienação; vinculando a estas formas as práticas administrativas identificadas a partir da análise dos critérios do PNQ, buscando ponderar de que maneira estas práticas atuam na consolidação do controle político-ideológico nas organizações participantes.

É importante salientar que um mesmo critério, por possuir variadas abordagens, pode constar em mais de uma forma de controle simultaneamente. Ademais, cabe ressalvar, da mesma forma que Faria (2004) realiza em sua obra ao propor esta divisão, que o isolamento das dimensões e formas de controle organizacional é concebido apenas para fins de análise. Concretamente, na realidade das organizações, estas dimensões e formas de controle atuam de maneira integrada.

\subsection{Forma hierárquico-burocrática de controle}

A conversão das atividades de vigilância e supervisão direta dos trabalhadores para um controle baseado na monitoria e avaliação de desempenho constitui uma relevante consequência da imposição do controle burocrático através da estrutura organizacional (FARIA, 2004).

O controle burocrático, em seu sentido contemporâneo, propicia a divisão sistemática do trabalho, na qual o desempenho é mensurado a partir de uma descrição precisa de deveres e direitos, cujo estabelecimento e alterações restringem-se a um seleto grupo pertencente à elite hierárquica (MOTTA, 1990).

Nesse sentido, há um forte vínculo entre os critérios Estratégias e Planos e Processos do PNQ, que possibilita a concepção das práticas promovidas nesses critérios como legitimadoras do poder concentrado na elite hierárquica das organizações participantes. Esses critérios visam 
expandir os mecanismos de monitoramento do alcance das metas e objetivos organizacionais, estabelecidos pela alta direção das organizações, centrados no aumento da produtividade.

Observa-se também, em particular no critério Processos, o esforço das práticas administrativas ali propostas em revestir as estruturas burocráticas das organizações de um caráter flexível, aduzindo uma hierarquia horizontalizada e adotando um discurso de apoio a um maior participacionismo na gestão organizacional.

Faria (2004) defende que, mesmo com esta flexibilidade alegada, a estrutura gerencial e o processo de trabalho fundamentam-se na lógica taylorista expandida. Ainda que a estrutura apresente um aparente achatamento, esta é claramente hierárquica e consistente com a forma burocrática de controle, com menores níveis na cadeia de comando.

Leal (2003) corrobora esta ideia ao ponderar que estruturas hierárquicas ditas flexíveis não passam de uma concentração sem centralização do poder, sendo enganosa a designação do termo “desburocratização” para esses casos. Para a mesma autora, nas organizações possuidoras de tais estruturas, a dominação da elite hierárquica é forte e informe.

Adicionalmente, quanto ao modelo participativo, Faria (2004) concebe a participação como uma forma de controle. Destarte, o participacionismo nas organizações tem por propósito: (i) conter o ímpeto reivindicatório dos trabalhadores, (ii) elevar a eficiência produtiva, e (iii) cooptar as lideranças dos trabalhadores, expandindo, assim, o controle gerencial.

Desmistifica-se, portanto, o participacionismo como humanizador do trabalho, sendo este modelo mais um mecanismo de controle empregado com o propósito de melhoria nos resultados. $\mathrm{O}$ participacionismo, efetivamente, ambiciona um sistema de avaliação de resultados como medida de eficiência, de valorização e de alcance de metas (FARIA, 2004).

\subsection{A disciplina nas unidades produtivas}

O conceito de disciplina pressupõe a docilidade dos corpos, condição que pode ser obtida seja através dos mecanismos de punição aos transgressores, seja através de recompensa aos obedientes. Destarte, disciplina implica um ato de coação, atingindo os agentes subjugados e tornando-os acessíveis às pretensões dos disciplinadores (FOUCAULT, 2011).

Isso posto, para Foucault (2011, p. 132) “a disciplina fabrica assim corpos submissos e exercitados, corpos 'dóceis"”. Igualmente, Foucault (2011, p. 132) complementa que "é dócil um corpo que pode ser submetido, que pode ser utilizado, que pode ser transformado e aperfeiçoado".

Essas definições de disciplina e docilidade contribuem para a compreensão dos mecanismos de controle inerentes aos critérios Liderança, Pessoas e Processos do PNQ. Os critérios Liderança e Processos fundamentam-se em práticas de gestão que objetivam estabelecer ações corretivas a serem aplicadas caso o trabalho não seja realizado nos padrões estabelecidos. Ademais, quanto ao critério Pessoas, este está essencialmente vinculado aos estímulos à cooperação, ao alcance das 
metas determinadas e às práticas de remuneração, incentivos e reconhecimento. O poder disciplinar, dessa forma, evidencia-se tanto nos mecanismos de correção quanto nas práticas de reconhecimento.

A disciplina caracteriza-se por sua dupla função, em que, simultaneamente, eleva as forças do corpo em termos de utilidade econômica, e limita essas mesmas forças em termos políticos. Dessa forma, "a coerção disciplinar estabelece no corpo o elo coercitivo entre uma aptidão aumentada e uma dominação acentuada" (FOUCAULT, 2011, p.134).

Garcia (1984, p. 55) observa que

normalizar os indivíduos, no poder disciplinar, constitui, a bem da verdade, uma arte de punir. Assim, na medida em que a pena caracteriza o castigo, da mesma forma que o prêmio caracteriza a recompensa, o operário tem que compreender qual o risco que ele corre ao faltar ao trabalho, ao incitar os companheiros à greve ou ao cometer quaisquer indisciplinas.

O participacionismo, os programas de corresponsabilidade, as equipes de trabalho e a flexibilização das linhas de montagem, características das organizações contemporâneas, introduzem no ambiente organizacional uma nova forma de punição, a autodisciplina (FARIA, 2004).

Se antes o controle personificava-se na figura do supervisor, a partir das mudanças introduzidas pelos princípios da gestão da qualidade, este passa a ser exercidos pelos próprios funcionários, de forma inconsciente. O poder disciplinar converte o controle localizável em um controle imperceptível (SILVA; ALCADIPANI, 2003).

Sobre as práticas da gestão da qualidade e seus impactos nas relações de poder e dominação, Silva e Alcadipani (2003, p. 13) observam que

[...] a organização do trabalho em equipes ditas semi-autonômas multiplica os 'olhos do poder'. Todos se transformam em vigias, todos garantem o seguimento das normas e ao mesmo tempo todos podem servir como examinadores. Uma vez que a alma dos indivíduos também se transformou em alvo do poder, é necessário que continuamente ela seja avaliada na sua relação com as idéias da organização.

Por fim, faz-se relevante reproduzir o pensamento de Foucault (2011, p. 134) que vai ao encontro da análise das novas formas de controle e punição quando observa que

Pequenas astúcias dotadas de um grande poder de difusão, arranjos sutis, de aparência inocente, mas profundamente suspeitos, dispositivos que obedecem a economias inconfessáveis, ou que procuram coerções sem grandeza, são eles entretanto que levaram à mutação do regime punitivo, no limiar da época contemporânea.

\subsection{A transmissão ideológica}

A repercussão da expansão das organizações burocráticas excede as instâncias sociais e políticas, atingindo a personalidade dos indivíduos. As organizações burocráticas, dessa forma, atuam na formação de um comportamento social cada vez mais homogeneizado, promovendo uma 
forma de perda da consciência e de experiência de vida de seus integrantes (MOTTA, 1990).

A busca pelo domínio do pensamento decorre da necessidade vista pela organização de afastar possíveis divergências na coletividade que as compõe. Esse controle se consolida através de um sistema ideológico responsável por criar e disseminar valores que legitimam o controle do pensamento e compartilham esses valores entre os agentes da organização (LEAL, 2003).

Os critérios Liderança e Clientes, presentes na avaliação do PNQ, sustentam-se em práticas voltadas à legitimação deste controle ideológico através da instituição de princípios e valores organizacionais que devem ser adotados por todos os agentes que a compõem.

Esses valores estão fortemente vinculados à cultura organizacional e se sustentam e se reproduzem a partir de discursos que buscam dissimular o antagonismo fundamental inerente às relações de produção. Faria (2004) observa que a gestão capitalista empenha-se em aprimorar apenas aquelas atitudes e competências dos trabalhadores que possam melhor acomodá-los aos mecanismos de controle da organização.

Com isso, muito dos valores e princípios difundidos pelas organizações "sob a égide da responsabilidade social", conforme aponta Leal (2003, p. 26), "são mercadologicamente valorizados, outorgando à ética e à moral um caráter, sobretudo utilitário".

Esta visão crítica dos valores e princípios organizacionais traz à tona o critério Sociedade do PNQ, que visa analisar e promover ações supostamente voltadas à responsabilidade socioambiental e ao desenvolvimento social.

Para Leal (2003), as organizações buscam revestir-se de uma imagem de "empresas cidadãs" visando persuadir os trabalhadores, expondo suas ações como oriundas de uma consciência social visando o bem geral, mascarando seu verdadeiro interesse nos retornos expressados em recursos financeiros, consolidação da imagem e dividendos políticos. Dessa forma, a noção de cidadania corporativa distorce o conceito legítimo de cidadania, que diz respeito "à superação dos interesses particulares em nome do bem comum, à liberdade, à igualdade, isto é, ao respeito pelos direitos do outro" (LEAL, 2003, p. 22).

Meneghetti (2007 p. 15) é ainda mais contundente ao afirmar que

[...] organizações de propriedade privada atendem, em última instância, aos interesses particulares, sendo possível, no entanto, por esse raciocínio, identificar discursos de empresas socialmente responsáveis; preocupadas com o bem-estar dos seus funcionários; voltadas para o bem-estar social, desde que a empresa não sinta ameaçado o seu lucro. Os atos praticados por uma organização têm em vista obter maior lucro possível com a menor punição, legal ou comercial, que possa vir a sofrer pelas práticas tidas como irresponsáveis.

Todo esse esforço em transparecer uma imagem de empresa cidadã, no que concerne aos mecanismos de poder, aponta para uma "metáfora da cidadania" que intenta suscitar nos empregados a responsabilidade de conduzir suas operações sempre da melhor forma, assumindo a responsabilidade pela satisfação dos clientes, internos e externos, e buscando a melhoria contínua 
em suas atividades (LEAL, 2003, p. 22).

Esta demanda constante pela satisfação de clientes internos e externos, nos leva ao critério Clientes do PNQ, que também possui seus preceitos vinculados às formas ideológicas de controle. A preocupação em atender, e até mesmo exceder, às necessidades dos clientes surge a partir do pressuposto da crescente competitividade mercadológica, que sujeita a sobrevivência da organização à satisfação destas necessidades (TURCHI, 1997).

Esse foco na melhoria contínua fundamenta-se na ideologia da empresa excelente, que compõe o imaginário organizacional e impõe um controle que mais se assemelha a um "culto à excelência”. A necessidade de superação de escalões ascendentes de qualidade dos produtos e serviços alastra-se pelas organizações na forma de uma "histeria coletiva" (LEAL, 2003, p. 24), instituindo nos agentes uma forma de autocontrole através do receio de serem superados ou de terem suas falhas expostas aos demais colegas de trabalho e clientes externos (CAPPELLE; FONSECA; MIRANDA, 2008).

Adicionalmente, Hopfer e Faria (2006 p. 9 -10) observam que o clima de competição interna suscitada a partir da internalização da busca irrefreável pela excelência, "cria processos conscientes e inconscientes, que mantém os indivíduos presos à ideia de sucesso, podendo transformar a organização numa prisão psíquica".

O conceito de melhoria contínua, que nunca vislumbra um fim, também reflete na forma quantitativa com que os critérios Processos e Resultados do PNQ ambicionam aferir os resultados da organização, no que Hopfer e Faria (2006, p. 9) denominam como "ideologia da materialidade da sociedade capitalista".

Uma particularidade pertinente em relação ao critério Resultados refere-se ao fato de que o mesmo não preconiza a descrição de práticas ou mecanismos administrativos para a sua avaliação. O critério é avaliado com base na divulgação, por parte da empresa participante do PNQ, da evolução dos dados quantitativos alusivos aos resultados econômico-financeiros relativos aos clientes e ao mercado, à sociedade, às pessoas, aos processos e aos fornecedores, dos últimos 3 anos.

Pressupõe-se, a partir de então, que este critério apresenta-se intimamente relacionado aos mecanismos de controle ideológico, através de uma imperiosa e permanente demanda pela melhora dos resultados quantificáveis da organização. Cabe acentuar, ainda, que, dos 1.000 pontos possíveis de serem alcançados pelas empresas participantes do PNQ, 450 pontos, ou 45 por cento do total, são obtidos a partir da análise deste critério.

Finalmente, o critério Pessoas do PNQ também evidencia formas de controle relacionadas à sua forma ideológica, através, sobretudo, das estratégias de treinamento, desenvolvimento e capacitação dos trabalhadores com vistas ao alcance das estratégias da organização. 
Villete (apud Faria, 2004 p. 109-10) destaca os dois níveis operados pelo treinamento. O primeiro refere-se ao desenvolvimento das aptidões inerentes ao desempenho da função do trabalhador e o segundo, essencialmente ideológico, intenta a internalização de comportamentos pretendidos pela organização.

Faria (2004) atenta que para a manutenção de uma determinada formação social, é primordial que esta reproduza suas condições de produção. Destarte, complementa que

\footnotetext{
a escola e os treinamentos nas empresas não apenas qualificam a força de trabalho e reproduzem a submissão à ideologia dominante para os operários, como reproduzem, para os agentes da exploração, as condições de manejar tal ideologia, de gerir o trabalho, de forma a assegurar a dominação (FARIA, 2004, p.108).
}

Ademais, Leal (2003) realça, ainda, a plausibilidade de um saber mais preciso se sobrepujar a um conhecimento mais amplo do trabalhado, objetivando alcançar tal finalidade.

\subsection{A alienação dos trabalhadores}

As críticas à consolidação das organizações burocráticas estão essencialmente vinculadas ao que Motta (1990, p. 47) chama de "roubo da vida", a apropriação, pela organização, daquilo que é mais estimado pelo sujeito. Tragtenberg (1980) atenta para a psicomanipulação nas organizações contemporâneas, onde não apenas a mais-valia é roubada do trabalhador, mas o seu próprio "ser" é arrebatado em função da sua produtividade, sendo a rentabilidade seu único desígnio.

$\mathrm{Na}$ alçada do critério Pessoas do PNQ, importa destacar o logro da atenção altruística das empresas ao bem-estar, à segurança e à saúde ocupacional de seus trabalhadores. Esses discursos, aliado às práticas de transmissão ideológica analisada na seção precedente, atuam na consolidação daquilo que Faria (2004) intitula como "sequestro da subjetividade".

O sequestro da subjetividade é, portanto, a alienação em sua forma sofisticada. Através dela, na forma objetiva, o indivíduo é destituído do controle do processo de trabalho, enquanto na ótica subjetiva, o sujeito deixa de possuir o controle sobre si (FARIA, 2004).

Dentre as cinco formas de sequestro da subjetividade identificadas na pesquisa de Faria e Meneghetti (2001, p.7), quando se analisa a alienação dos trabalhadores a partir da internalização dos discursos e valores organizacionais, o "sequestro pelo envolvimento total" requer destaque na medida em que suscita um "sentimento de entrega à sedução e ao encantamento proporcionados pelos valores da empresa, que atuam como aliciantes de comprometimento".

Faria (2004, p. 118) adverte que

o seqüestro da subjetividade pode desencadear formas de idealização (do Mito Fundador, do Presidente da Empresa, da própria Empresa, do Grupo), em que o trabalhador age mais como um ator que tem um papel a desempenhar e que pode inclusive apaixonar-se por este papel, do que como um sujeito, ser do desejo e da ação.

A relação que emerge da dominação subjetiva exemplifica o que, no plano da psicologia, 
intitula-se como Síndrome de Estocolmo, quando se estabelecem ligações afetivas entre sequestrador e sequestrado. Deve-se elucidar, também, que a utilização do termo "sequestro" em detrimento de outros que possam denotar uma tomada definitiva da subjetividade do trabalhador, ocorre de maneira proposital, de forma que se subentende a possibilidade de resgate dessa mesma (FARIA, 2004).

Com a sujeição dos indivíduos aos mecanismos de controle que atuam na tomada do inconsciente, promovendo a alienação dos trabalhadores, estes passam a adotar o ideal coletivo incutido pela empresa, em detrimento do ideal do ego individual (MOTTA, 1981).

Motta (1981 p.38) observa, ainda, que

o indivíduo, submetendo-se totalmente (de corpo e alma: diríamos), trabalha para a organização como para si próprio. Ele experimenta o sentimento de que a organização faz parte dele, da mesma forma que ele faz parte da organização, sentimento este que o liga ao futuro da organização. Há, portanto, uma tomada do indivíduo pela organização em nível do inconsciente [...].

Concomitantemente à tomada da subjetividade do sujeito pela organização ocorre uma anulação da instância crítica (MOTTA, 1981), impossibilitando que estes sujeitos assimilem, conscientemente, a precariedade e intensidade dos ritmos de trabalho que lhes são impostos, características fundamentais dos novos modelos de produção (FARIA, 2004).

A intensificação do ritmo de trabalho, alicerçada na alienação dos trabalhadores, passa também pelas novas tecnologias da informação aplicadas na sustentação das operações e processos de trabalho. A análise do emprego dessas tecnologias para alavancar os negócios, bem como as estratégias aplicadas ao desenvolvimento e proteção dos ativos intangíveis e do conhecimento organizacional, compõe o cerne do critério Informações e Conhecimentos do PNQ.

Para Faria (2004), o modelo de produção toyotista, hegemônico nas organizações atuais, em nada difere do modelo fordista senão pelo incremento das recentes tecnologias de base microeletrônica, constituindo assim um neofordismo.

A utilização das novas tecnologias de informação e comunicação tem expandido o controle das organizações, especialmente sobre a dimensão cognitiva dos trabalhadores, por trazer consigo uma necessidade de melhor compreensão dos processos e das tarefas a serem executados (NASCIMENTO; PEREIRA; SEGRE, 2013).

Jarveenpa e Lang (2005) identificaram em sua pesquisa que, simultaneamente ao empoderamento advindo da introdução das tecnologias móveis nas organizações, houve uma privação da liberdade altamente prezada pelos sujeitos. Menos tempo para atividades pessoais, aumentos na pressão e na percepção do monitoramento e da vigilância no trabalho foram citados na pesquisa dos autores supracitados como repercussões negativas da introdução das novas tecnologias no ambiente organizacional. 
Esse paradoxo empoderamento/escravização emergido das recentes tecnologias que proporcionam uma conectividade permanente corrobora a percepção de intensificação e sofisticação dos mecanismos de controle fundamentados na alienação dos trabalhadores, impondo um autocontrole que compele aos indivíduos estar sempre conectados ao trabalho, mesmo naqueles momentos dedicados a família e ao lazer (NASCIMENTO; PEREIRA; SEGRE, 2013).

\section{Considerações finais}

O Prêmio Nacional da Qualidade foi concebido com o intuito de reconhecer e premiar aquelas empresas referências na excelência em gestão no Brasil. Esta avaliação emprega critérios de análise alicerçados nos princípios da gestão da qualidade que, na perspectiva das teorias administrativas hegemônicas, constituem autênticos mandamentos da gestão organizacional.

Este artigo ambicionou analisar as práticas de gestão identificadas a partir da dissecação dos princípios que fundamentam cada critério de avaliação do PNQ e seus impactos nas formas de controle político-ideológico nas organizações participantes.

Quanto à primeira forma de controle político-ideológico proposta por Faria (2004), a forma hierárquico-burocrática, identificou-se, nos critérios Estratégias e Planos e Processos, mecanismos de consolidação do controle e de concentração das decisões em uma elite hierárquica das empresas, bem como se elucidaram os mecanismos de controle e centralização do poder intrínsecas no conceito hegemônico de flexibilização da estrutura organizacional.

Em relação ao controle disciplinar, nos critérios Liderança, Pessoas e Processos, foi analisado de que forma tanto os mecanismos de correção, quando os resultados do trabalho fogem ao padrão esperado, quanto as práticas de reconhecimento, os incentivos e a remuneração atuam de modo a docilizar os trabalhadores, inibindo sua capacidade crítica e instituindo o controle disciplinar da organização sobre seus indivíduos.

No controle por transmissão ideológica, identificaram-se, inicialmente, os valores e princípios organizacionais atrelados ao critério Liderança como mecanismos de transmissão e legitimação do controle ideológico nas organizações. O critério Pessoas, através dos treinamentos e programas de desenvolvimento vinculados a este, busca não somente ampliar a capacidade produtiva e de geração de resultados dos trabalhadores, mas, principalmente, reproduzir a ideologia da elite organizacional. Os critérios Clientes e Sociedade buscam incutir nos trabalhadores a ideologia da melhoria contínua, um verdadeiro culto a excelência que nunca tem fím, além da inculcação da imagem de uma empresa cidadã e preocupada com o bem-estar social na qual o trabalhador deve espelhar seu comportamento. Completando a forma de controle por transmissão ideológica, os critérios Processos e Resultados, sendo este último o de maior peso atribuído no cálculo do PNQ, atuam de forma a transmitir e reproduzir a ideologia da materialidade da sociedade 
capitalista, onde o desempenho de uma empresa é mensurado e analisado unicamente sob a luz de seus resultados quantitativos.

Por fim, na forma de controle por alienação, identificou-se no critério Pessoas, e na sua suposta preocupação com o bem-estar do trabalhador, um relevante mecanismo de controle da força de trabalho através do seqüestro da subjetividade, quando o até mesmo o "ser" dos trabalhadores é roubado em função do aumento da sua produtividade e sujeição aos objetivos e diretrizes da organização. Ademais, quanto ao critério Informações e Conhecimento, verificou-se a consolidação do controle pela alienação dos indivíduos a partir da implementação das novas tecnologias móveis que vêm sendo empregadas no dia a dia dos trabalhadores. A utilização destas novas tecnologias da informação e comunicação privam os indivíduos de sua liberdade, impondo-os a necessidade de se manterem sempre conectados ao trabalho, mesmo em seus momentos de lazer ou dedicados à família, bem como contribuem para que o indivíduo conviva com a sensação de constante monitoramento e vigilância do seu trabalho.

A conclusão deste trabalho, longe de ter alcançado um desfecho para o tema, aponta para um inquietante questionamento acerca da concepção hegemônica de excelência que predomina nos estudos em administração. Os resultados obtidos a partir da pesquisa realizada neste artigo, ainda que restrita a análise documental, apontam não apenas para uma intensificação dos sistemas de controle político-ideológico, bem como para uma sofisticação sagaz destes mecanismos, corolário da adoção de práticas anunciadas como fomentadoras da excelência em gestão.

Além de intensificar o controle sobre o corpo e a mente dos trabalhadores, as práticas de gestão que supostamente atestariam excelência na gestão organizacional, atuam de modo a tornarem mais difícil sua percepção e, consequentemente, a emancipação dos indivíduos frente a esta realidade.

Os resultados atestam o que Faria (2004) observa em sua obra que dá origem ao campo de estudos da Economia Política do Poder, quando afirma que

[...] o capital, através de suas práticas e da ideologia da gestão capitalista, desde o taylorismo-fordismo, até a chamada gestão (produção) flexível ou toyotismo, investiu na sofisticação dos mecanismos de controle, sem, contudo, abandonar os mecanismos iniciais (2004 p. 161).

Por fim, fica aqui o incentivo de novos estudos que busquem elucidar os mecanismos explícitos e os cultos de controle, nas suas mais diferentes formas, presentes nas práticas e estratégias administrativas das organizações contemporâneas e que contribuam para o adensamento das formas de resistências que vêm sendo desenvolvidas através dos esforços dos teóricos críticos e, como Motta (1990 p. 19) observa, dos "setores sociais comprometidos com a transformação [...] e com a construção de uma teoria organizacional reflexiva, que sirva à mudança do estabelecido". 


\begin{abstract}
This article analyzes the management model proposed by the eight evaluation criteria of the National Quality Award (PNQ) and the impact on forms of political-ideological control in the participating companies. For this purpose, at first the concepts of quality management that underlie the National Quality Award are examined, as well as his eight criteria and their approaches. Additionally, the thematic of control is discussed in the light of the Critical Theory of Control, conceived as a field of study of the Political Economy of Power proposed by Faria (2004). It was verified that the management practices identified through the dissection of the criteria of the National Quality Award not only contribute to the intensification, but also to the sophistication of the political-ideological mechanisms of control present in the organizations that purport to follow them as a benchmark of excellence in management. The conclusions of this study raise questions about the hegemonic conception of management excellence prevalent in studies in administration, seeking to help build an organizational theory that serves to elucidate the mechanisms of control over the workers mind and body and instigate his emancipation front this reality.
\end{abstract}

Keywords: organizational control; national quality award; political economy of power.

\title{
Referências
}

ABRASIL. Programa PBQP - programa brasileiro de qualidade e produtividade. Disponível em http://www.abrasil.gov.br/nivel3/index.asp?id=182\&cod=BUSCA

ALCADIPANI, R.; DAVEL, E. Estudos críticos em administração: a produção científica brasileira nos anos 1990. RAE, São Paulo, v. 43, n.04, p. 72-85, 2003.

CANÇADO, A. C.; TENÓRIO, F. G.; PEREIRA, J. R.. Gestão Social: reflexões teóricas e conceituais. Cadernos EBAPE.BR (FGV), v. 9, n. 3, Rio de Janeiro, Set. 2011, p. 681-703.

CUNHA, M. P.; CUNHA, J. V. DAHAB, S. Gestão da qualidade: uma abordagem dialética. Revista de Administração Contemporânea. Edição Especial. 2001, p.197-215.

FARIA, J. H. de. Economia política do poder: as práticas do controle nas organizações. Curitiba: Juruá, 2004. v. 3.

FARIA, J. H. de. Teoria crítica em estudos organizacionais no Brasil: o estado da arte. Cadernos Ebape.br, Rio de Janeiro, v. 7, p.510-515, set. 2009.

FARIA, J. H. de.; MENEGHETTI, F. K.. O sequestro da subjetividade e as novas formas de controle psicológico no trabalho: uma abordagem crítica ao modelo toyotista de produção.In.Anais... XXV ENANPAD. Campinas, 2001.

FARIA, J. H. de; HOPFER, K. R. Controle por resultados no local de trabalho: dissonâncias entre o prescrito e o real. RAE eletrônica, São Paulo, v. 5, n. 1, 2006.

FARIA, J. H. Economia política do poder: as práticas do controle nas organizações. Curitiba: Juruá, 2004. v. 3.

FERNANDES, W. A.. O movimento da qualidade no Brasil. São Paulo: Essential Idea, 2011.

FOUCAULT, M. Vigiar e punir. 39². Ed. Petrópolis: Vozes, 2011.

FUNDAÇÃO NACIONAL DA QUALIDADE. Avalie-se. Disponível em: <http://www.fnq.org.br/avalie-se/pnq>. Acesso em: 18 junho 2013

FUNDAÇÃO NACIONAL DA QUALIDADE. Critérios de excelência: avaliação e diagnóstico da gestão organizacional. $19^{\circ}$. Ed., São Paulo, 2012.

GARCIA, F. C. Ação patronal, poder e organização no setor siderúrgico de Minas Gerais. São Paulo: ERA. V. 24, n. 3, p. 55-66, jul.-set., 1984.

INVERNIZZI, N. Novos rumos do trabalho: Mudanças nas formas de controle e qualificação da força de trabalho 
brasileira. 2000. 487 f. Tese (Doutorado) - Curso de Política Científica e Tecnológica, Unicamp, Campinas, 2000.

IRANDA, A. R. A.; CAPPELLE, M. C. A.; FONSECA, F. P. Controle Ideológico: uma reflexão teórica sobre os princípios que orientam as práticas da gestão da qualidade. In: ENANPAD, 32., 2008, Rio de Janeiro. Anais... Rio de Janeiro: Anpad, 2007. p. 1 - 15.

JARVENPAA, S.L.; LANG K.R. Managing the paradoxes of mobile technology. Information Systems Management, v. 22, n. 4, 2005. crossref

LEAL, A. P. Universidades Corporativas e controle social: as faces da habituação e da instrumentalização do sujeito trabalhador em uma organização multinacional da área de logística. 2003. Dissertação (Mestrado) Curitiba:

Universidade Federal do Paraná, 2003.

MARTINS, F. R. Controle: perspectivas de análise na teoria das organizações. Cadernos Ebape.br, Rio de Janeiro, v. 4, n. , p.1-14, mar. 2006.

MENEGHETTI, F. K. Liberdade ou autonomia: reflexões críticas sobre as organizações. In: ENANPAD, 31, 2007, Rio de Janeiro. Anais... Rio de Janeiro: Anpad, 2007. p. 1 - 16.

MOTTA, F. C. P., BRESSER-PEREIRA, L. Introdução à Organização Burocrática. São Paulo: Editora Brasiliense S. A., 1987.

MOTTA, F. C. P. O poder disciplinar nas organizações formais. Revista de Administração e Empresas, v. 21, n. 4, p. 33-41, 1981. cross ref

MOTTA, F. C. P. Organização e poder: empresa, estado e escola. São Paulo: Editora Atlas, 1990.

MOTTA, F. C. P. Controle social nas organizações. Revista de Administração de Empresas. v. 33, n. 5, p. 68-87. Set/Out de 1993.

PAES DE PAULA, A. P. Maurício Tragtenberg: contribuições de um marxista anarquizante para os estudos organizacionais críticos. RAP - Revista Brasileira de Administração Pública, Rio de Janeiro, v. 42, p. 949-968, 2008.

PEREIRA, C. L.; SEGRE, L. M.; NASCIMENTO, R. P. A ampliação das estruturas de controle por meio das tecnologias de informação e comunicação: a onipresença do "pan-óptico eletrônico" no setor bancário. Cadernos Ebape.br, Rio de Janeiro, v. 5, n. , p.65-84, mar. 2013.

RAMOS, A. G. A Redução Sociológica - Introdução ao Estudo da Razão Sociológica. Rio de Janeiro: Edições Tempo Brasileiro Ltda, 1965.

SILVA, J. V. R.; SILVA, K. V. M.da. Poder e ideologias: a domesticação dos dominados. In: ENANPAD, 35., 2011, Rio de Janeiro. Anais... Rio de Janeiro: Anpad, 2011. p. 1 - 16.

SILVA, R. C.; ALCADIPANI, R..Manda quem pode, obedece quem tem juízo: a consolidação da disciplina através da participação na Siderúrgica Rio-Grandense, In: Encontro Anual da ANPAD, 27., 2003, Atibaia, SP. Anais... Curitiba: ANPAD, 2003

TRAGTENBERG, M. Administração, poder e ideologia. São Paulo: Moraes, 1980.

TRAGTENBERG, M. Burocracia e ideologia. São Paulo: Editora UNESP, 2006. crossref

TURCHI, L. M. Qualidade total: afinal de que estamos falando? Texto para discussão. Brasília, v. 459, 1997.

VIEIRA, M. M. F.; CALDAS, M. P. Teoria crítica e pós-modernismo: principais alternativas à hegemonia funcionalista. RAE-clássicos, São Paulo, v. 46, n., p.59-70, mar. 2006.

WOOD JUNIOR, T.; URDAN, F. T. Gerenciamento da qualidade total: uma revisão crítica. RAE, São Paulo, v. 34, n., p.46-59, dez. 1994. 


\section{Dados dos autores}

Nome completo: Rudinei Machado de Abreu Junior

Filiação institucional: Universidade Federal de Santa Catarina - UFSC

Departamento: Programa de Pós-graduação em Administração - CPGA

Função ou cargo ocupado: Mestrando e bolsista de pesquisa GM/CNPq

Endereço completo para correspondência: Rua Nilo Cordeiro Dutra, $n^{\circ}$ 90, Bairro Saco dos Limões, Florianópolis - SC, Brasil. CEP 88.040-650.

Telefone para contato: (48) 9111-5686

e-mail: rudineijr@gmail.com

Nome completo: Sidnei Manoel Rodrigues

Filiação institucional: Universidade Federal de Santa Catarina - UFSC

Departamento: Programa de Pós-graduação em Administração - CPGA

Função ou cargo ocupado: Mestrando

Endereço completo para correspondência: Rua Santos Saraiva, 238, Apto 503 - Estreito Florianópolis - SC, Brasil. CEP 88070-570.

Telefone para contato: (48) 9104-6224

e-mail: sidneimr@sc.senai.br

Nome completo: Bruno Henrique Figueiredo Baldez

Filiação institucional: Universidade Federal de Santa Catarina - UFSC

Departamento: Programa de Pós-graduação em Administração - CPGA

Função ou cargo ocupado: Mestrando

Endereço completo para correspondência: Rua Deputado Antônio Edu Vieira, 1422. Ap. 616 Bairro Agronômica. Florianópolis - SC, Brasil. CEP: 88040-001

Telefone para contato: (48) 9915-7119

e-mail: bbaldez@gmail.com

Nome completo: Luis Moretto Neto

Filiação institucional: Universidade Federal de Santa Catarina - UFSC

Departamento: Programa de Pós-graduação em Administração - CPGA

Função ou cargo ocupado: Professor Adjunto da UFSC

Endereço completo para correspondência: CAD/UFSC - Universidade Federal de Santa Catarina, Campus Universitário Reitor João David Ferreira Lima, Bairro Trindade, Florianópolis, Santa Catarina, CEP 88040- 970.

Telefone para contato: (48) 3721-9374 Ramal: 204 
e-mail:moretto@cse.ufsc.br

Submetido em: 20/09/2013

Aceito em: 16/10/2014 